\title{
Condicionantes da Tempestividade das Prestações de Contas Contábeis no Terceiro Setor
}

\author{
Conditioning on the Temptability of Rendering of Accounts in the Third Sector
}

Laís Amélia Revoredo de Paula*a; Maria Aparecida do Nascimento Cavalcanti Marques ${ }^{\mathrm{b}}$; Roberto Silva da Penha ${ }^{\mathrm{c}}$

${ }^{a}$ Universidade Federal do Rio Grande do Norte. RN, Brasil.

'Universidade Federal Rural do Rio de Janeiro. RJ, Brasil.

'Universidade Federal de Uberlândia, Programa de Pós-Graduação em Ciências Contábeis. MG, Brasil.

*E-mail: laisrevoredo@hotmail.com

\begin{abstract}
Resumo
O Terceiro Setor compreende as atividades voluntárias realizadas pela sociedade civil voltadas para o atendimento do interesse público. O objetivo da pesquisa foi identificar os principais fatores que influenciam na prestação de contas das Organizações da Sociedade Civil de Interesse Público (OSCIP) das entidades situadas no Estado do Rio Grande do Norte. Foi realizada uma pesquisa descritiva, na qual se utilizou como instrumento para a coleta de dados um survey direcionado aos gestores das 38 entidades qualificadas como OSCIP e que possuem o registro no portal do Cadastro Nacional de Entidades Sociais do Ministério da Justiça (CNES/MJ). Os resultados demonstraram que 50\% das instituições não possuem os relatórios de prestação de contas disponíveis no portal CNES/MJ, apesar dos gestores entenderem a prestação de contas como uma forma de continuarem percebendo recursos. No que tange aos fatores identificados como passíveis de influenciar na prestação de contas, verificou-se que as entidades que possuem mais tempo de qualificação têm algum órgão específico dentro da organização e que o fato de ter uma contabilidade interna favorece a prestação de contas. Outro achado importante é que na percepção dos respondentes, o prazo estipulado para a prestação de contas é insuficiente comprometendo a adimplência por parte das entidades.
\end{abstract}

Palavras-chave: Terceiro Setor. Prestação de Contas. OSCIP.

\begin{abstract}
The third sector comprises voluntary activities carried out by civil society aimed at meeting the public interest. The objective of the research is to identify the main factors that influence the accountability of Civil Society Organizations of Public Interest (OSCIPS) of entities located in the state of Rio Grande do Norte. A descriptive research was carried out in which a survey was conducted as a tool for the data collection directed to the managers of the 38 entities qualified as OSCIPs and that have the registration in the portal of the National Register of Social Entities of the Ministry of Justice (CNES / MJ). The results showed that 50\% of institutions do not have the reporting reports available on the CNES/MJ portal, although managers see accountability as a way to continue to perceive resources. Regarding the factors identified as capable of influencing the accountability, it was verified that the entities that have more qualification time have some specific organ within the organization and that the fact of having an internal accounting favors the rendering of accounts. Another important finding is that in the respondents 'perception, the deadline for accountability is insufficient, jeopardizing compliance by the entities.
\end{abstract}

Keywords: Third Sector. Accountability. OSCIP.

\section{Introdução}

O Terceiro Setor nasceu como uma alternativa na realização de atividades de cunho social, que deveriam ser desempenhadas pelo Estado. Essa iniciativa surgiu com a ascensão do protestantismo, pois este se baseia nos valores fundamentais do ser humano, os quais estão intimamente ligados com a solidariedade, o amor ao próximo, a ética e a responsabilidade social (PAES, 2004).

Por volta das décadas de 1960 e 1970 , o desenvolvimento de atividades filantrópicas foi aflorado no Brasil e o período da ditadura militar refletiu, de modo positivo, para desenvolvimento do Terceiro Setor, pois surgiram várias organizações e movimentos sociais com o objetivo de combater o autoritarismo imposto e a desigualdade social. Como resultado, houve um grande crescimento de associações civis, movimentos sociais e grupos ambientalistas na luta pela defesa de minorias (PAES, 2004).
Diante do cenário de desigualdade social e ineficiência do Estado se observou um crescimento do Terceiro Setor, o qual foi impulsionado pela insuficiência de políticas públicas adequadas, que contribuíssem para a minimização das ocorrências de problemas sociais. Como resposta a esta carência, pessoas jurídicas de direitos privado se uniram para promover ações de responsabilidade social e, atualmente, através de parcerias com Estado buscam atender as demandas de bens e serviços públicos necessários à sociedade (BEHRING; BOSCHETTI, 2007).

No cerne dessa discussão se verifica um aumento na busca de recursos pelas entidades sem fins lucrativos e, consequentemente, observa-se também um aumento no nível de exigência nas informações prestadas por essas entidades, resguardando a transparência e os resultados organizacionais (SANTOS et al., 2008).

A prestação de contas, na visão do Conselho Federal 
de Contabilidade (CFC, 2003), refere-se ao conjunto de documentos e informações disponibilizados pelos dirigentes das entidades aos órgãos interessados e autoridades, possibilitando analisar e julgar as contas, como também auxiliar na gestão dos administradores, ou seja, visa demonstrar os resultados obtidos pelas entidades, corroborando através das demonstrações contábeis para a conservação das atividades das entidades sem fins lucrativos, possibilitando ainda a continuidade na captação de recursos.

Considerando que nas últimas décadas houve um grande crescimento das organizações da sociedade civil, foi criada uma qualificação para as instituições que atuam na produção de bens e serviços para toda sociedade ou parte dela, de forma a oferecer maior credibilidade a essas organizações. Dessa forma, a criação do título de Organizações da Sociedade Civil de Interesse Público - OSCIP serviu para estabelecer critérios entre as organizações que realmente têm finalidade pública.

É nesse contexto que se destaca a importância de analisar os fatores que influenciam a prestação de contas dessas entidades, uma vez que a Lei $n^{\circ}$ 9.790/1990 foi instituída com a finalidade de trazer uma maior compreensão para o entendimento da classificação dessas entidades, tendo em vista que simplificou os procedimentos de qualificação, como é o caso das OSCIP.

O objetivo dessa pesquisa foi identificar os principais fatores que influenciam na prestação de contas das OSCIP das entidades situadas no Estado do Rio Grande do Norte. Conforme o Conselho Federal de Contabilidade (CFC, 2003), a prestação de contas é considerada umas das principais obrigações dos gestores das OSCIP, posto que requer informações com exigências específicas. É de grande importância a identificação dos fatores que influenciam a prestação de contas, tendo em vista se tratar de parcerias realizadas pelo Estado através do repasse de recursos públicos. Destarte, a prestação de contas é considerada uma das ferramentas de maior êxito na fiscalização da aplicação de tais verbas.

\section{Material e Métodos}

\subsection{Caracterização da pesquisa}

$\mathrm{Na}$ abordagem, esta pesquisa é qualitativa, pois sua principal característica é analisar a interação entre as variáveis, buscando ainda compreender os fenômenos que ocorrem entre essas (BEUREN, 2012). Quanto aos procedimentos adotados se caracteriza como levantamento ou survey, pois se buscou a obtenção de informações de determinada população, através da aplicação de survey.

\subsection{Universo e amostra da pesquisa}

O presente trabalho se destinou a analisar as entidades do Terceiro Setor intituladas como OSCIP, as quais estão listadas no site do Ministério da Justiça. A escolha dessas entidades se deveu ao fato de estarem inseridas no contexto de transição do
Terceiro Setor, pois a lei que as regulamenta trouxe um novo parâmetro de enquadramento e desburocratização.

Das 56 organizações listadas no sítio eletrônico do Ministério da Justiça, até a data da pesquisa, 21 de agosto de 2013, foram excluídas da base as entidades que não preencheram na internet o sistema do (CNES/MJ), bem como aquelas que adquiriram o título no ano de 2013, restando apenas 38 entidades para análise. Portanto, foram selecionadas 38 entidades para responderem ao survey. A seleção se orientou pela disponibilização de telefone ou e-mail para contato. As 38 entidades foram contatadas por e-mail, solicitando que respondessem ao questionário da pesquisa. Em alguns casos, foi necessária a realização de ligações, além do reenvio do questionário por e-mail para que procedessem com a participação positiva na pesquisa.

Dessa forma, foram analisados os questionários de 11 das 38 OSCIP, nos anos compreendidos entre 2000 a 2012, sendo verificado, ainda, se as mesmas possuíam a prestação de contas eletrônica disponível na internet.

\subsection{Construção do survey e método de análise}

O questionário da pesquisa foi elaborado com o intuito de obter a percepção dos gestores das OSCIP quanto aos fatores que influenciam na prestação de contas das entidades, dada a devida importância à elaboração e para a divulgação das demonstrações contábeis e se os mesmos acham relevante o papel da contabilidade como um instrumento de auxílio de gestão. O questionário foi dividido em 4 etapas de questões:

A $1^{\text {a }}$ etapa, identificação do gestor: nesta etapa foram incluídas questões que permitem descrever algumas características dos entrevistados: função que ocupa na instituição, gênero, idade e nível de escolaridade.

A $2^{\mathrm{a}}$ etapa, identificação do responsável pela prestação de contas: foram formuladas questões sobre a formação acadêmica do responsável pela prestação de contas, vínculo contratual do responsável pela elaboração das demonstrações contábeis, tempo de duração do vínculo, gênero e idade média do responsável.

A $3^{\mathrm{a}}$ etapa, informações gerais sobre a entidade: nesta etapa foram formulados quesitos sobre o ramo de atuação da instituição e tempo de obtenção do título.

$4^{\text {a }}$ etapa, abordadas questões a respeito da percepção dos gestores sobre o tema em questão: sendo estabelecidos pontos a respeito dos benefícios da posse do título de qualificação, informações inerentes ao conhecimento dos relatórios de prestação de contas, nível de exigência dos agentes financiadores em relação à prestação de contas, se o prazo estipulado para a apresentação dos relatórios é suficiente e a função da contabilidade.

Os dados foram analisados por meio da percepção quanto ao nível de concordância dos respondentes. No questionário aplicado foi atribuído pontuação de 1 a 7 para os quesitos formulados. Sendo que, os itens de 1 a 3 remetem 
a discordância do respondente quanto ao tema $(1=$ discordo totalmente, 2 = discordo muito e 3 = discordo pouco), já o item 4 é tido como indiferente e de 5 a 7 atribuem concordância quanto ao tema abordado $(5=$ concordo pouco, $6=$ concordo muito e 7 = concordo totalmente).

\section{Resultados e Discussão}

Através da análise se buscou traçar um perfil dos prestadores de contas das entidades do Terceiro Setor, classificadas como OSCIP.

\subsection{Análise das informações divulgadas no portal CNES/ MJ}

O Quadro 1 foi elaborado considerando a população citada anteriormente na metodologia, dessa forma, salienta-se que foram consideradas as OSCIP que obtiveram o título de qualificação até o ano 2012. As entidades foram consideradas a partir do ano 2000, tendo em vista que foi o ano subsequente à criação da lei que promulgou as OSCIP.

Quadro 1 - Ano de qualificação como OSCIP.

\begin{tabular}{|c|c|c|c|}
\hline $\begin{array}{c}\text { Ano de } \\
\text { Qualificação }\end{array}$ & Frequência & $\begin{array}{c}\text { Percentual } \\
\%\end{array}$ & $\begin{array}{c}\text { Percentual } \\
\text { acumulado }\end{array}$ \\
\hline De 2000 até 2002 & 9 & $17 \%$ & $17 \%$ \\
\hline Entre 2003 e 2004 & 13 & $24 \%$ & $41 \%$ \\
\hline Entre 2005 e 2006 & 14 & $26 \%$ & $67 \%$ \\
\hline Entre 2007 e 2008 & 9 & $17 \%$ & $84 \%$ \\
\hline Entre 2009 e 2010 & 3 & $5 \%$ & $89 \%$ \\
\hline De 2011 até 2012 & 6 & $11 \%$ & $100 \%$ \\
\hline Total & 54 & $100 \%$ & \\
\hline
\end{tabular}

Fonte: Dados da Pesquisa.

Observa-se que nos anos compreendidos entre 2003 a 2006, houve aumento relativo no deferimento dos títulos de qualificação como OSCIP outorgados pelo Ministério da Justiça, no entanto, também se verifica que, a partir do ano de 2007, houve decréscimo das emissões desse título. O Ministério da Justiça esclarece que o número expressivo de indeferimentos, nos pedidos de qualificação, ocorreu principalmente pela não observância da legislação pertinente pelas entidades, bem como a ausência de balanço patrimonial ou demonstração do resultado do exercício, a ausência de DIPJ (ou termo de compromisso), participação de servidor público na diretoria da entidade, prestação onerosa de serviços de educação ou saúde e pela ausência de cláusulas estatutárias obrigatórias.

Quanto às entidades sem fins lucrativos que realizaram o registro por meio do portal do CNES/MJ, totalizando 38 instituições, verificou-se que algumas entidades não tinham o relatório de prestação de contas disponibilizado.

Salienta-se que desde 2007, todas as OSCIP precisam realizar, anualmente, a prestação de contas eletrônica, através do CNES/MJ. O processo de cadastramento se inicia com o registro das informações prestadas eletronicamente, em que essas informações também são impressas e enviadas ao Ministério da Justiça pelos correios, de acordo com as instruções contidas no sistema de prestação de contas anual e no manual do usuário.

Esse processo está dividido em duas fases, a primeira fase se refere ao registro do responsável e dos dados básicos da entidade. Posteriormente, após a comprovação do vínculo do responsável, a entidade terá acesso ao sistema de prestação de contas. É importante destacar que o prazo estabelecido para prestação de contas das instituições qualificadas como OSCIP deve ocorrer até a data de 31 de maio, todos os anos. Caso contrário, essas podem perder a certidão de regularidade. Tal certidão é considerada um instrumento de transparência da instituição, pois assevera o atendimento aos requisitos legais e regulamentares pelas entidades, além de que é exigida pelos órgãos governamentais para o repasse de recursos públicos ou doações.

Isso posto, o Ministério da Justiça ainda acrescenta que, a entidade que não demonstrou o relatório anual de prestação de contas não perde a qualificação de imediato, porém fica em situação irregular. E as empresas que realizarem doações a essas entidades ficam privadas de deduzi-las. Além do mais, o Poder Público não poderá realizar parcerias com essas entidades. E ainda, caso as entidades persistirem em não apresentar a prestação de contas, durante três anos seguidos, poderão perder a qualificação como OSCIP.

Diante das razões expostas, buscou-se primeiramente, identificar os motivos pelos quais a prestação de contas não estava disponível no sítio eletrônico, uma vez que a entidade já teria efetivado o seu cadastro. Portanto, nota-se no Quadro 2 que $50 \%$ das entidades não tiveram seus relatórios divulgados, muito embora, a partir do ano de 2007 houve uma redução de aproximadamente $46 \%$ das entidades, que não tiveram o relatório de prestação de contas divulgados, se comparado ao período correspondente de 2000 a 2006, tal diminuição pode ser atribuída ao fato de que a prestação de contas passou a ser realizada em meio eletrônico. O que favoreceu o envio dos relatórios.

Quadro 2 - Entidades cadastradas no CNES/MJ.

\begin{tabular}{|c|c|c|c|c|}
\hline Ano de & \multicolumn{2}{|c|}{ Entidades Cadastradas } & \multicolumn{2}{|c|}{ Entidades Qualificadas } \\
\cline { 2 - 5 } Qualificação & Frequência & $\begin{array}{c}\text { Percentual } \\
\%\end{array}$ & Frequência & $\begin{array}{c}\text { Percentual } \\
\%\end{array}$ \\
\hline $\begin{array}{c}\text { De 2000 até } \\
2002\end{array}$ & 7 & $13 \%$ & 9 & $17 \%$ \\
\hline $\begin{array}{c}\text { Entre 2003 e } \\
2004\end{array}$ & 5 & $9 \%$ & 13 & $24 \%$ \\
\hline $\begin{array}{c}\text { Entre 2005 e } \\
2006\end{array}$ & 13 & $24 \%$ & 14 & $26 \%$ \\
\hline $\begin{array}{c}\text { Entre 2007 e } \\
2008\end{array}$ & 6 & $11 \%$ & 9 & $17 \%$ \\
\hline $\begin{array}{c}\text { Entre 2009 e } \\
2010\end{array}$ & 2 & $4 \%$ & 3 & $6 \%$ \\
\hline $\begin{array}{c}\text { De 2011 até } \\
2012\end{array}$ & 5 & $9 \%$ & 6 & $11 \%$ \\
\hline Total & 38 & $70 \%$ & 54 & $100 \%$ \\
\hline
\end{tabular}

Fonte: Dados da Pesquisa. 
Concomitantemente, também foi notado que apesar dessa diminuição, a prestação de contas das entidades, com registro no CNES/MJ, não tive seus relatórios divulgados, uma explicação para isso é que, de acordo com o Ministério da Justiça, foram disponibilizados os relatórios de prestação de contas já aprovados pela Secretaria Nacional de Justiça (SNJ).

As informações do Quadro 3 demonstram que das 38 entidades cadastradas somente 50\% tiveram seus relatórios de prestação de contas apresentados em alguns dos anos compreendidos entre 2006 a 2012, apesar da apresentação da prestação de contas eletrônica somente ser exigida a partir de 2007.

Conforme pode ser observado no Quadro 3, 50\% das entidades tiveram seus relatórios aprovados pela SNJ e publicados no CNES/MJ. As entidades que obtiveram o título de qualificação antes de 2007 tiveram representatividade de $29 \%$ no quesito correspondente à divulgação dos relatórios de prestação de contas.
Quadro 3 - Entidades com prestação de contas divulgadas entre 2000 a 2012

\begin{tabular}{|c|c|c|c|c|}
\hline \multirow{2}{*}{$\begin{array}{c}\text { Ano de } \\
\text { Qualificação }\end{array}$} & \multicolumn{2}{|c|}{$\begin{array}{c}\text { Prestação de Contas } \\
\text { Divulgadas }\end{array}$} & \multicolumn{2}{|c|}{ Entidades Cadastradas } \\
\cline { 2 - 5 } & Frequência & Percentual & Frequência & Percentual \\
\hline $\begin{array}{c}\text { De 2000 até } \\
2002\end{array}$ & 5 & $13 \%$ & 7 & $18 \%$ \\
\hline $\begin{array}{c}\text { Entre 2003 e } \\
2004\end{array}$ & 1 & $3 \%$ & 5 & $13 \%$ \\
\hline $\begin{array}{c}\text { Entre 2005 e } \\
2006\end{array}$ & 5 & $13 \%$ & 13 & $34 \%$ \\
\hline $\begin{array}{c}\text { Entre 2007 e } \\
2008\end{array}$ & 5 & $13 \%$ & 6 & $16 \%$ \\
\hline $\begin{array}{c}\text { Entre 2009 e } \\
2010\end{array}$ & 1 & $3 \%$ & 2 & $5 \%$ \\
\hline $\begin{array}{c}\text { De 2011 até } \\
2012\end{array}$ & 2 & $5 \%$ & 5 & $13 \%$ \\
\hline Total & 19 & $50 \%$ & 38 & $100 \%$ \\
\hline
\end{tabular}

Fonte: Dados da Pesquisa.

A partir dos dados levantados no Quadro 4 se verifica que as instituições sem fins lucrativos, que possuem a qualificação de OSCIP há mais de cinco anos possuem maior probabilidade de apresentar seus relatórios e esses serem aprovados e divulgados no site.

Quadro 4 - Entidades com relatórios divulgados entre os anos de 2007 a 2012

\begin{tabular}{|c|c|c|c|c|c|c|}
\hline \multirow{2}{*}{ Ano de Qualificação } & \multicolumn{2}{|c|}{$\begin{array}{c}\text { Prestação de Contas em Anos } \\
\text { Consecutivos }\end{array}$} & $\begin{array}{c}\text { Prestação de Contas em Anos } \\
\text { Alternados }\end{array}$ & \multicolumn{2}{c|}{ Total } \\
\cline { 2 - 7 } & Frequência & Percentual & Frequência & Percentual & Frequência & Percentual \\
\hline De 2000 até 2002 & 2 & $5 \%$ & 3 & $8 \%$ & 5 & $13 \%$ \\
\hline Entre 2003 e 2004 & 0 & $0 \%$ & 1 & $3 \%$ & 1 & $3 \%$ \\
\hline Entre 2005 e 2006 & 3 & $8 \%$ & 2 & $5 \%$ & 5 & $13 \%$ \\
\hline Entre 2007 e 2008 & 4 & $11 \%$ & 1 & $3 \%$ & 5 & $13 \%$ \\
\hline Entre 2009 e 2010 & 0 & $0 \%$ & 1 & $3 \%$ & 1 & $3 \%$ \\
\hline De 2011 até 2012 & 2 & $5 \%$ & 0 & $0 \%$ & 2 & $5 \%$ \\
\hline Total & 11 & $29 \%$ & 8 & $21 \%$ & 19 & $50 \%$ \\
\hline
\end{tabular}

Fonte: Dados da Pesquisa.

Das sete entidades com registro no CNES/MJ e que foram qualificadas a partir de 2009, apenas três possuem a prestação de contas disponibilizadas. Uma provável resposta para esse questionamento é que as entidades mais antigas detêm melhor organização e maiores condições de investir em pessoal qualificado para que estes procedam com a elaboração dos relatórios.

\subsection{Análise das respostas do survey}

O Quadro 5 apresenta a relação das OSCIP respondentes dos questionários com o tempo de qualificação. Dessa maneira, se observa que $29 \%$ das entidades responderam ao questionário.

Quadro 5 - Tempo de qualificação x OSCIP respondente do questionário

\begin{tabular}{|c|c|c|c|c|}
\hline $\begin{array}{c}\text { Tempo de Obtenção do } \\
\text { Título }\end{array}$ & $\begin{array}{c}\text { OSCIP Respondentes do } \\
\text { Questionário }\end{array}$ & Percentual & $\begin{array}{c}\text { OSCIP Registradas no } \\
\text { CNES/MJ }\end{array}$ & Percentual \\
\hline Até 2 anos & 1 & $3 \%$ & 5 & $13 \%$ \\
\hline De 5 a 10 anos & 4 & $11 \%$ & 26 & $68 \%$ \\
\hline Acima de 10 anos & 6 & $16 \%$ & 7 & $18 \%$ \\
\hline Total & 11 & $29 \%$ & 38 & $100 \%$ \\
\hline
\end{tabular}

Fonte: Dados da Pesquisa.

Verifica-se que a maioria das OSCIP analisadas, ou seja, $16 \%$ da população respondente do questionário possui qualificação acima de 10 anos. O que caracteriza essas instituições como sendo mais conservadoras, no sentido de manter suas relações de transparência com o Poder Público.

No Quadro 6 se observou entre os respondentes da pesquisa que $55 \%$ correspondem ao sexo masculino. Ambos os sexos têm representatividade de $64 \%$ no que se refere à idade média dos 
respondentes, esta compreendida entre 35 e 50 anos. Quanto ao grau de instrução, todos possuem nível superior, sendo $18 \%$ em contabilidade e $72 \%$ em diversas áreas: Administração, Geologia, Pedagogia e Gestão de Políticas Públicas.

Quadro 6 - Identificação dos respondentes do questionário.

\begin{tabular}{|l|c|c|c|c|c|c|c|}
\hline & \multicolumn{2}{|c|}{ Gênero } & \multicolumn{3}{c|}{ Idade } & \multicolumn{2}{c|}{ Grau de Instrução } \\
\hline & Fem. & Masc. & Até 35 anos & De 35 a 50 anos & Acima de 50 anos & $\begin{array}{c}\text { Superior em } \\
\text { Contabilidade }\end{array}$ & $\begin{array}{c}\text { Outros cursos } \\
\text { superiores }\end{array}$ \\
\hline Quant. & 5 & 6 & 3 & 7 & 1 & 2 & 9 \\
\hline Perc. \% & 45 & 55 & 27 & 64 & 9 & 18 & 82 \\
\hline Total & \multicolumn{2}{|c|}{$\mathbf{1 1}$} & \multicolumn{3}{|c|}{$\mathbf{1 1}$} & & $\mathbf{1 1}$ \\
\hline
\end{tabular}

Fonte: Dados da Pesquisa.

No contato realizado com as entidades foi solicitado que os questionários fossem respondidos, preferencialmente, pelos gestores ou pelo responsável financeiro. Todavia, observou-se que os respondentes da pesquisa (Quadro 7), em maior parte, ocupavam o cargo de coordenador, com representatividade de $27 \%$ e os demais, cerca de $18 \%$, ocupam cargo de diretor, gerente e administrador. As respostas do questionário podem ter uma possível relação entre si, no que diz respeito ao cargo/ função que ocupam (Quadro 7) e ao grau de instrução (Quadro 6). De acordo com os dados acima se observa no Quadro 6, que todos os respondentes possuem nível superior de escolaridade e compreendem uma faixa etária entre 35 e 50, o que induz a pensar que as OSCIP são conduzidas por administradores mais experientes.

Quadro 7 - Cargo/função que o respondente ocupa na instituição

\begin{tabular}{|c|c|c|c|}
\hline Cargo/Função & Frequência & Percentual \% & $\begin{array}{c}\text { Percentual } \\
\text { Acumulado }\end{array}$ \\
\hline Presidente & 1 & $9 \%$ & $9 \%$ \\
\hline Diretor & 2 & $18 \%$ & $27 \%$ \\
\hline Contador & 1 & $9 \%$ & $36 \%$ \\
\hline Coordenador & 3 & $27 \%$ & $64 \%$ \\
\hline Gerente & 2 & $18 \%$ & $81 \%$ \\
\hline Administrador & 2 & $18 \%$ & $100 \%$ \\
\hline Total & 11 & $100 \%$ & \\
\hline
\end{tabular}

Fonte: Dados da Pesquisa.

No que tange a análise da prestação de contas, o questionário foi dividido em dois blocos. Sendo um no intuito de caracterizar o responsável pela prestação de contas, analisando a formação do responsável pela elaboração das demonstrações contábeis, seu vínculo e tempo contratual, bem como o gênero e idade desse profissional. Essa primeira etapa inclui também questionamentos acerca do ramo de atuação e tempo de obtenção do título de OSCIP pela entidade.

Já no segundo bloco de questões foi analisada a percepção do gestor da entidade acerca do tema em questão, qual seja a análise dos fatores que influenciam a prestação de contas das entidades do Terceiro Setor, sobretudo, as OSCIP.

Para o primeiro bloco de questões foi analisada, inicialmente, a formação do responsável pela prestação de contas aosórgãos fiscalizadores. Dototal de 11 entidades, apenas três prestações de contas não são realizadas por profissionais da contabilidade, correspondendo a aproximadamente $27 \%$. Enquanto que os contadores respondem por aproximadamente $73 \%$ dos casos, e em valores absolutos por oito empresas.

Com relação ao vínculo contratual do responsável pela elaboração das demonstrações contábeis, verificou-se que há uma uniformidade nas respostas. Dos 11 respondentes, cinco indicaram elaborar as demonstrações através de empresas de contabilidade, caracterizados como pessoa jurídica, e apenas uma entidade utiliza um prestador de serviço pessoa física, sendo as demais executadas por funcionário e contador da própria entidade (Quadro 8).

Quadro 8 - Vínculo contratual do responsável pela prestação de contas

\begin{tabular}{|c|c|c|c|c|c|c|}
\hline & Escritório de Contabilidade & Funcionário da Entidade & \multicolumn{2}{c|}{ Contador Individual } \\
\hline Tempo de Titulação & Frequência & Percentual & Frequência & Percentual & Frequência & Percentual \\
\hline Até 02 anos & 1 & $20,0 \%$ & 0 & $0,0 \%$ & 0 & $0,0 \%$ \\
\hline De 03 a 05 anos & 0 & $0,0 \%$ & 0 & $00,0 \%$ & 0 & $0,0 \%$ \\
\hline De 06 a 10 anos & 1 & $20,0 \%$ & 3 & $60,0 \%$ & 1 & $00,0 \%$ \\
\hline Acima de 10 anos & 3 & $60,0 \%$ & 2 & $40,0 \%$ & 1 & $100,0 \%$ \\
\hline Total & $\mathbf{5}$ & $\mathbf{1 0 0 \%}$ & $\mathbf{5}$ & $\mathbf{1 0 0 , 0} \%$ & $\mathbf{1}$ & $\mathbf{1 0 0 , 0} \%$ \\
\hline
\end{tabular}

Fonte: Dados da Pesquisa.

Na tentativa de verificar se há alguma relação com o tempo de qualificação como OSCIP, percebe-se que as maiores frequências se referem a períodos de titulação superior a cinco anos. Verifica-se, portanto, que as entidades que possuem o título de qualificação há mais tempo possuem também algum órgão de contabilidade dentro da instituição, o que pode acabar contribuindo, mesmo que indiretamente, para a elaboração de contas de modo tempestivo.

$\mathrm{Na}$ sequência foi analisada a visão dos respondentes sobre conhecimentos inerentes a elaboração e divulgação dos relatórios de prestação de contas, em que se procurou identificar a percepção dos gestores quanto aos elementos que 
devem conter nos relatórios de prestação de contas.

A análise se restringiu a percepção dos respondentes quanto aos elementos que devem compor o relatório de prestação de contas Q1, bem como a prestação inerente ao termo de parceria Q2. Verificou-se que 55\% dos respondentes afirmam ter pleno conhecimento dos principais documentos que devem compor esses relatórios, o resultado médio das repostas foi de 6,27 para Q1 e 6,45 para Q2 (Quadro 9).

Tabela 9 -Elementos que compõem o termo de parceria

\begin{tabular}{|l|c|c|}
\hline \multicolumn{3}{|c|}{ Análise Descritiva } \\
\hline & Q. 1 & Q. 2 \\
\hline Média & 6,27 & 6,45 \\
\hline Desvio Padrão & 1,009 & 0,688 \\
\hline Mínimo & 4 & 5 \\
\hline Máximo & 7 & 7 \\
\hline
\end{tabular}

Fonte: Dados da Pesquisa.

Também foi investigada a relação existente sobre a obtenção de recursos com a divulgação das demonstrações Q3 e o papel do Estado como agente financiador de fonte de recursos é considerado exigente com relação à apresentação do relatório de prestação de contas Q4, em que se percebeu considerável grau de relevância quanto ao assunto, ou seja, concordam muito.

Os resultados demonstram que a obtenção de recursos está intimamente ligada à divulgação das demonstrações, apresentando uma representatividade de 90\%. Pois o Governo, no papel de agente financiador, é considerado bastante exigente com relação à apresentação do relatório de prestação de contas, o que é confirmado pela média apresentada no Quadro 10 .

Quadro 10 - Informações de auxílio à gestão

\begin{tabular}{|l|c|c|}
\hline \multicolumn{3}{|c|}{ Análise Descritiva } \\
\hline & Q. 3 & Q. 4 \\
\hline Média & 6,09 & 6,64 \\
\hline Desvio Padrão & 1,044 & 0,505 \\
\hline Mínimo & 4 & 6 \\
\hline Máximo & 7 & 7 \\
\hline
\end{tabular}

Fonte: Dados da Pesquisa.

$\mathrm{Na}$ formulação do quesito a respeito de se os relatórios contábeis fornecidos com atraso comprometem a gestão da entidade, foi alcançada a média 6,64. Dessa maneira, compreende-se que grande parte dos respondentes atribuem que os atrasos no fornecimento dos relatórios implicam no comprometimento da gestão, bem como no repasse de recursos.

Buscou-se apresentar a atribuição dada pelos respondentes quanto ao prazo para envio dos relatórios de prestação de contas, verificando se o período estipulado pelo Ministério da Justiça, $1^{\circ}$ de janeiro a 31 de maio, era o suficiente para a correta elaboração e envio Q5. A resposta quanto a Q5 possuiu um índice médio de 4,27. Essa preocupação se justifica pelo fato de haver imposição, por parte da lei, que rege essas organizações, no que tange a prestação de contas, sobretudo, por essas estarem sujeitas a perda dos benefícios caso não prestem contas no prazo estipulado, bem como deixarão de receber repasse de recursos.

A Q6 trata do fato da contabilidade funcionar, interna ou externamente, à entidade poder ser fator determinante para a confecção em tempo hábil dos relatórios exigidos, a média de respostas foi de 5,45 (Quadro 11).

Quadro 11 - Prazo para elaboração dos relatórios

\begin{tabular}{|l|c|c|}
\hline \multicolumn{3}{|c|}{ Análise Descritiva } \\
\hline & Q. 5 & Q. 6 \\
\hline Média & 4,27 & 5,45 \\
\hline Desvio Padrão & 1,850 & 1,510 \\
\hline Mínimo & 1 & 3 \\
\hline Máximo & 7 & 7 \\
\hline
\end{tabular}

Fonte: Dados da Pesquisa.

Em seguida, foi investigado se a entidade tinha conhecimento sobre instrumentos de gestão, no que diz respeito à avaliação e ao controle de desempenho. E se a mesma atribuía grande relevância para a adoção dessas ferramentas para que procedesse com a elaboração das demonstrações contábeis, como também se as informações geradas pela contabilidade auxiliavam na análise dos indicadores Q7.

Com a média obtida com as respostas, 6,27, conclui-se que as entidades que atribuem um maior grau de importância a esses indicadores desempenham uma melhor gestão, Quadro 12.

Quadro 12 - Informações geradas pelos instrumentos de gestão

\begin{tabular}{|l|c|c|}
\hline \multicolumn{3}{|c|}{ Análise Descritiva } \\
\hline & Q. 7 & Q. 8 \\
\hline Média & 6,27 & 5,27 \\
\hline Desvio Padrão & 0,786 & 1,794 \\
\hline Mínimo & 5 & 1 \\
\hline Máximo & 7 & 7 \\
\hline
\end{tabular}

Fonte: Dados da Pesquisa.

No entanto, quando questionado se os sistemas contábeis geram informações de maneira eficaz, a ponto de descartar uma equipe especializada de contabilidade Q8, a média de resposta foi de 5,27 sugerindo haver concordância nesse quesito atribuindo (Quadro 12).

\section{Conclusão}

Atendeu-se ao objetivo proposto neste estudo, que foi identificar como principal fator passível de influenciar a prestação de contas das OSCIP, a carência de um profissional de contabilidade dentro da instituição, pois a presença desse profissional contribuiria para o envio dos relatórios de modo tempestivo.

Este estudo teve, contudo, como limitação o acesso às informações no site do Ministério da Justiça, pois como a prestação de contas precisa de uma aprovação do SNJ, se apresentou impossibilitada análise das entidades que não tiveram seus relatórios divulgados, essas foram classificadas como não prestaram contas. 
Para estudos futuros é sugerido que seja feita uma verificação com essa metodologia em outras OSCIP de localização geográfica distinta, pois os achados desta pesquisa podem conter influências regionais, e com resultados em regiões distintas podem se consolidar estes achados ou indicar que foram resultados atípicos.

\section{Referências}

ASSIS, M.S.; MELLO, G.R.; SLOMSKI, V. Transparência nas entidades do Terceiro Setor: a demonstração do resultado econômico como instrumento de mensuração de desempenho. In: São Paulo: USP, 2006.

BEUREN, I.M. Como elaborar trabalhos monográficos em contabilidade: teoria e prática. São Paulo: Atlas, 2012.

BEHRING, E.R.; BOSCHETTI, I. Politica social: fundamentos e história. São Paulo: Cortez, 2007.

BRASIL. Lei $\mathrm{n}^{\circ}$ 9.790, de 23/03/1999. Dispõe sobre a qualificação de pessoas jurídicas de direito privado, sem fins lucrativos, como Organizações da Sociedade Civil de Interesse Público, institui e disciplina o Termo de Parceria, e dá outras providências. Disponível em: <http://www.planalto.gov.br/ ccivil 03/leis/19790.htm>. Acesso em: 19 out. 2018.

CHAGAS, M.J.R.; ARAÚJO, A.O.; DAMASCENA, L.G Evidenciação das subvenções e assistências governamentais recebidas pelas OSCIPs: Uma análise empírica nos estados da
Paraíba e do Rio Grande do Norte. Rev. Amb. Contábil, v.3, n.2, p.100-115, 2011

CFC - Conselho Federal de Contabilidade. Manual de procedimentos contábeis para fundações e entidades de interesse social. Brasília: CFC, 2003.

FALCONER, A.P. A promessa do Terceiro Setor: um estudo sobre a construção do papel das organizações sem fins lucrativos e do seu campo de gestão. São Paulo: USP, 1999.

FERRAREZI, E. O novo marco legal do terceiro setor no Brasil. In: ENCONTRO DA REDE LATINO-AMERICANA E DO CARIBE DA SOCIEDADE INTERNACIONAL DE INVESTIGAÇÃO DO TERCEIRO SETOR RESEARCH (ISTR) - PERSPECTIVAS LATINO AMERICANAS SOBRE O TERCEIRO SETOR. Buenos Aires, 2001. Anais... Disponível em: $\quad<$ http://lasociedadcivil.org/docs/ciberteca/ferrarezi.pdf $>$ Acesso em: 21 out. 2018.

OLAK, P.A.; NASCIMENTO, D.T. Contabilidade para entidades sem fins lucrativos (terceiro setor). São Paulo: Atlas, 2010.

PAES, J.E.S. Fundações e entidades de interesse social: aspectos jurídicos, administrativos, contábeis e tributários. Brasília: Brasília Jurídica, 2004.

REGULES, L.E.P. Terceiro setor: Regime Jurídico das OSCIP. São Paulo: Método, 2006.

SANTOS, D.P. et al. Demonstração do valor adicionado: aplicação em uma instituição do terceiro setor de Minas Gerais. Enfoque Reflexão Contábil, v.27, n.3, p.45-56, 2008. 